\title{
A AULA DE EDUCAÇÃO FÍSICA E AS PRÁTICAS CORPORAIS: A VISÃO CONSTRUIIDA POR MENINAS EVANGÉLICAS
}

\author{
THE PHYSICAL EDUCATION CLASS AND BODILY PRACTICES: A VIEW BUILT \\ BY EVANGELICAL GIRLS
}

\author{
LA CLASE DE EDUCACIÓN FÍSICA Y LAS PRÁCTICAS CORPORALES: LA \\ VISIÓN CONSTRUIDA POR NIÑAS EVANGÉLICAS
}

Ana Carolina Capellini Rigoni*, Jocimar Daolio*

\begin{abstract}
Palavras chave: Práticas corporais. Educação Física. Religião.

Resumo: Para aqueles que compartilham de uma visão religiosa do mundo, as práticas cotidianas, consciente ou inconscientemente, são mediadas pelo conhecimento religioso. Isto se aplica às práticas corporais presentes na escola. Buscamos, neste artigo, compreender como meninas evangélicas, pertencentes à Assembleia de Deus e à Congregação Cristã, significam as práticas corporais na vida cotidiana, atribuindoIhes sentidos que são produzidos num processo relacional entre a Igreja e a aula de Educação Física (EF). O que constatamos, a partir de pesquisa etnográfica, é que a visão das meninas sobre as práticas corporais é produzida numa tensão cotidiana entre o que aprendem na Igreja e nas aulas de EF.
\end{abstract}

Keywords: Body practices. Physical Education. Religion.

Palabras clave: Prácticas corporales. Educación Física. Religión.

Abstract: For those who share a religious view of the world, everyday practices are consciously or unconsciously mediated by religious knowledge. This applies to bodily practices present at school. This article looks into how evangelical girls belonging to the Assemblies of God and the Christian Congregation signify bodily practices in everyday life, ascribing them meanings that are produced in a relational process - between the Church and the Physical Education (PE) class. Based on ethnographic research, we found that the girls' view of bodily practices is produced under everyday tension between what they learn in Church and in PE classes.

Resumen: Para aquellos que comparten una visión religiosa del mundo, las prácticas cotidianas, consciente o inconscientemente, son mediadas por el conocimiento religioso. Esto se aplica a las prácticas corporales presentes en la escuela. Buscamos, en este artículo, entender cómo las niñas evangélicas, pertenecientes a la Asamblea de Dios y a la Congregación Cristiana, dan significado a las prácticas corporales en la vida cotidiana, asignándoles sentidos que son producidos en un proceso relacional entre la Iglesia y la clase de Educación Física (EF). Lo que observamos, a partir de la investigación etnográfica, es que la visión de las niñas acerca de las prácticas corporales se produce dentro de una tensión cotidiana entre lo que aprenden en la Iglesia y en las clases de Educación Física.
*Universidade Metodista de Piracicaba (UNIMEP). Piracicaba, SP, Brasil. E-mail: anacarolinarigoni@yahoo. com.br

Recebido em: 05-02-2016 Aprovado em: 12-08-2016

(c) (i) () Licence 


\section{INTRODUÇÃO}

Falar sobre Educação Física (EF) implica, de algum modo, falar sobre corpo. Isto, por si só, já é motivo suficiente para que a EF seja alvo de preocupação para determinados grupos religiosos, como a Assembleia de Deus (AD) e a Congregação Cristã (CC), por exemplo, que são denominações religiosas comprometidas com a vigilância e a educação do comportamento de seus fiéis. Considerado por tais Igrejas como a parte "mundana" do ser humano, longe de permanecer na obscuridade, o corpo é parte central do processo educativo de fiéis dessas denominações. Algumas Igrejas possuem, inclusive, regimentos internos com sessões inteiramente dedicadas às regras que devem ser aplicadas ao corpo de seus membros, como bem nos mostra Kachia Téchio (2011).

Para aqueles que compartilham de uma visão religiosa do mundo, aos moldes do que é produzido na $A D$ e na $C C$, toda e qualquer prática, consciente ou inconscientemente, será mediada pelo conhecimento produzido no âmbito da religiosidade. No caso das práticas corporais, sejam elas conteúdos escolares ou extraescolares, isto também se aplica. Há um investimento por parte da Igreja em tudo que está relacionado ao uso do corpo pelo fiel. Com isso, não estamos dizendo que as Igrejas elaboram um culto ou evangelizações específicas para ensinar seus membros a se portarem diante das aulas de EF. Não é necessário, por exemplo, que um pastor fale especificamente para as meninas que elas não devem realizar certos movimentos ou não devem participar de determinadas atividades. Todas as meninas/ alunas que já foram por nós estudadas ${ }^{1}$ afirmam que o pastor e a professora de evangelização não falam explicitamente que elas não podem participar das aulas de EF. $O$ assunto entra em pauta apenas em momentos específicos, como aqueles em que elas se veem frente a um problema com algum professor, ou porque resolvem confrontar os pais na tentativa de serem autorizadas a participar de alguma atividade. Afora esses momentos, no decorrer da vida cotidiana, elas simplesmente "sabem" o que devem e o que não devem fazer.

Se nem sempre a participação dessas meninas é proibida de maneira formalizada, encontramos, no entanto, casos mais extremos, nos quais elas são formalmente proibidas. 0 documento na próxima página é uma carta recebida pelo professor de EF de uma escola por nós pesquisada solicitando afastamento de uma aluna das aulas práticas de EF. É possível notar que a carta não foi escrita e nem assinada pelos pais, mas sim pelo "Dirigente" (pastor) da Igreja.

Esta carta é apenas um dos inúmeros exemplos de impedimento ou de constrangimento vivenciados principalmente por meninas evangélicas em relação aos "usos do corpo2". Podemos citar, ainda, os casos nos quais o constrangimento é causado pela vestimenta, comumente utilizada por mulheres em igrejas clássicas ${ }^{3}$.

Partimos do pressuposto de que nesta relação de aprendizagem cotidiana, que é fruto de um diálogo ou embate entre a religião e outras esferas, a EF pode estabelecer uma relação

\footnotetext{
1 Aquelas que estudamos ao longo das pesquisas de mestrado e doutorado.

2 Longe de compactuar com visões dualistas, o termo "usos do corpo", utilizado por Marcel Mauss (2003), ganha sentido quando pensado em relação à ideia de educação do corpo no sentido de suas expressões e fisicalidades, uma vez que estamos frisando um tipo de educação que influencia comportamentos, posturas, vestuários, gestos, etc.

3 Normalmente as mulheres de igrejas clássicas só podem usar saias abaixo do joelho e em cores discretas. Ao falarmos de "denominações clássicas estamos nos referindo às igrejas pentecostais que foram inseridas no Brasil no início do século XX. Segundo Freston (1996), o pentecostalismo clássico brasileiro tem início com a implantação da Congregação Cristã, em 1910, e com a Assembleia de Deus, em 1911. Essas denominações guardam diferenças exorbitantes se comparadas àquelas que se inserem no Brasil depois da década de 1950 e, principalmente, daquelas que chegam ao país no final da década de 1980, chamadas de neopentecostais, como a Igreja Universal do Reino de Deus.
} 
de tensão no processo de construção do corpo de pessoas evangélicas. A EF pode, por meio de seus conteúdos, mobilizar certas reflexões capazes de levar o conhecimento produzido exclusivamente na igreja a outros patamares.

Figura 1 - Carta do pastor à escola

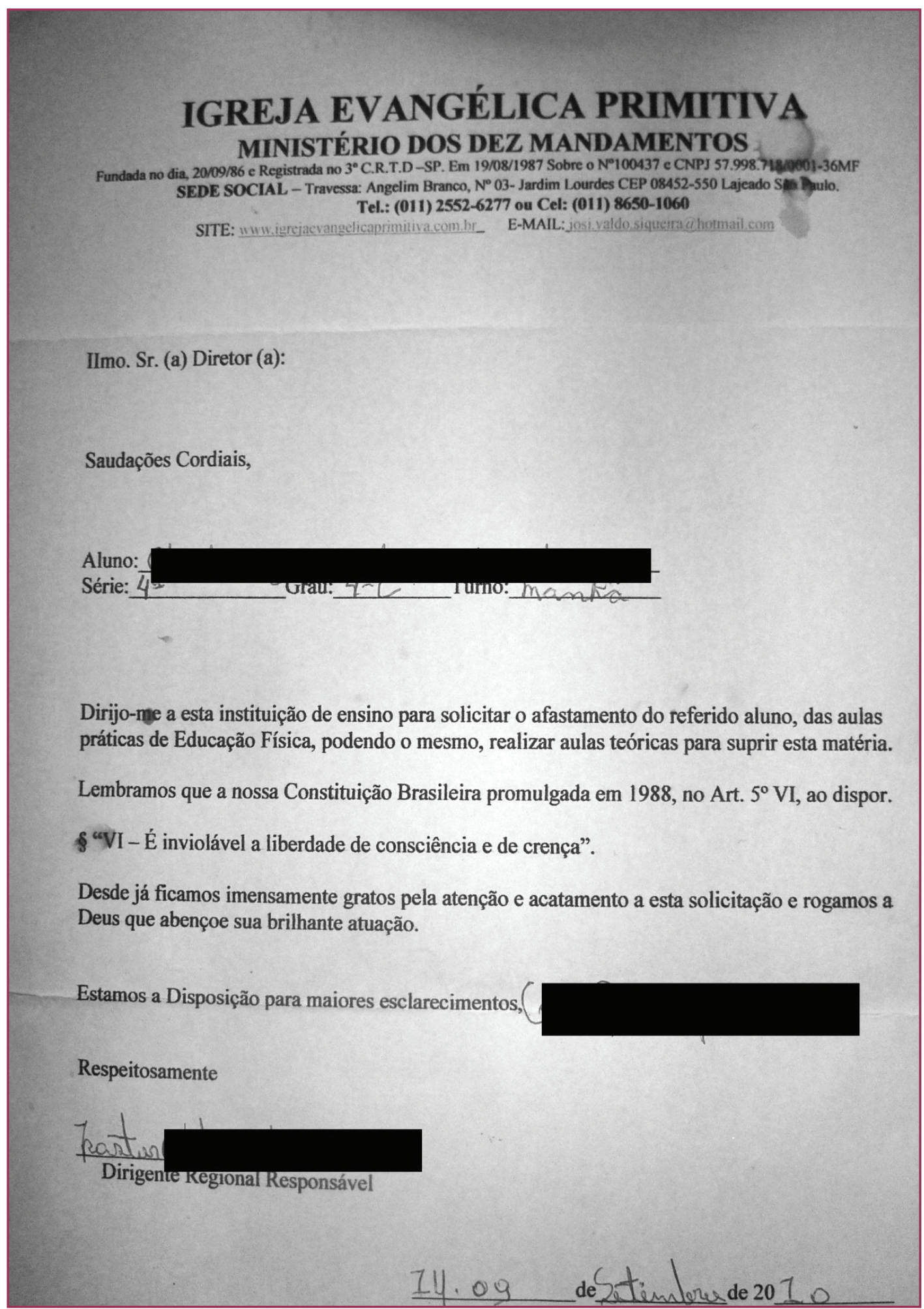

Fonte: RIGONI, A. C. C. (fotografia). Material de pesquisa de campo (2010).

Foi partindo desse cenário e da interpretação mais "amadurecida" dos dados analisados ao longo dos últimos anos, entre as pesquisas de mestrado e doutorado, que buscamos, neste 
artigo, refletir sobre as visões de corpo e de práticas corporais produzidas por meninas evangélicas de denominações clássicas, como a AD e a CC. A intenção foi compreender, especificamente, como essas meninas significam as práticas corporais na vida cotidiana, atribuindo-lhes sentidos que são produzidos num processo relacional (Igreja e Escola). 0 que constatamos foi que a visão das meninas sobre as práticas corporais é produzida numa tensão cotidiana entre o que aprendem na igreja e nas aulas de EF. Ainda que isto tenha sido constatado, é preciso frisar o quão notável é o modo como a religião medeia grande parte das relações escolares dessas meninas, influenciando suas visões sobre a EF e as práticas corporais.

Este texto é, portanto, fruto de pesquisa etnográfica e estudos aprofundados no âmbito da Educação Física e da Antropologia da Religião, realizados ao longo dos últimos dez anos (RIGONI, 2008, 2013). Apesar de citarmos, ao longo do texto, comentários de meninas estudadas anteriormente (em 2007 e 2008), a maioria dos dados diz respeito especificamente à etnografia realizada numa escola estadual do município de Campinas/SP. As reflexões, porém, foram e são constantemente atualizadas. Foram pesquisados diversos alunos do ensino médio, durante as aulas de EF e outros momentos de convivência, como intervalos, recreios, festividades, etc. A imersão no campo de pesquisa foi intensa e duradoura, já que passamos na escola grande parte dos dias letivos entre os anos de 2010 e 2012. Os instrumentos utilizados na realização da etnografia foram, principalmente, a observação e o registro no caderno de campo, bem como a realização de entrevistas semiestruturadas com as alunas selecionadas. As entrevistas foram todas gravadas e, posteriormente, transcritas para a preparação das análises. Isto possibilitou, como nos ensina Geertz (1989), a elaboração de uma "descrição densa" dos comportamentos e representações das meninas estudadas. De maneira mais específica, focamos a pesquisa em cinco meninas do $2^{\circ}$ ou $3^{\circ}$ ano do ensino médio, que frequentavam a $A D$ ou a CC. São elas 4 : Ana Julia (15 anos - AD); Sirléia (15 anos - AD, filha de pastor); Maria (15 anos - CC, neta de pastor); Renata (16 anos - CC) e; Letícia (16 anos - AD). Todas elas são de classe média baixa e frequentavam assiduamente os cultos e atividades de suas igrejas.

Embora o estudo tenha sido localizado, pois estudamos casos, igrejas e turmas escolares específicos, acreditamos, como defende Fonseca $(1999)^{5}$, que tais análises podem colaborar para uma compreensão mais ampla no que diz respeito às visões que meninas educadas em famílias evangélicas de denominações clássicas possuem sobre corpo, práticas corporais e a disciplina de EF.

\section{EDUCAÇÃO CORPORAL: ENTRE O ACEITAR E O TRANSGREDIR}

Como já havíamos constatado em pesquisas anteriores, as meninas investigadas agem de maneiras muito diversas. Segundo Rigoni (2013), devido às diferentes formas de educação a que são submetidas, elas parecem estabelecer uma espécie de negociação entre os usos e costumes postulados pela igreja e as necessidades geradas em outros âmbitos do cotidiano, como a escola e rua, por exemplo. Ou seja, apesar de serem religiosas, se for preciso, para não parecerem tão diferentes e não ficarem de fora de certas atividades, elas deixam de lado as opiniões da igreja e articulam suas ações pautadas em outros conhecimentos. Isso poderia demonstrar uma espécie de enfraquecimento dos ensinamentos religiosos institucionais,

4 Todos os nomes utilizados são fictícios. 
que estariam perdendo espaço para outras esferas da vida cotidiana. No entanto, como já apontou Pierucci (1997), isso demonstra não o enfraquecimento das instituições, mas uma transformação no modo como elas gerem seus conteúdos. Podemos afirmar a partir de experiências empíricas anteriores que a $\mathrm{AD}$ e a $\mathrm{CC}$, apesar de se esforçarem para manter seus "usos e costumes" (termo por eles utilizado), precisam se mostrar aptas às novas demandas (menos conservadoras) para não assistirem seus templos se esvaziando.

Percebe-se, no entanto, que, mais do que de seus líderes, é da membresia mais antiga da igreja que as tentativas de resistência parecem partir. Isso pode ser percebido na frase de uma das meninas estudadas:

Tem irmãs na igreja que não concordam com nada que você faça no teu corpo. Se eu corto o cabelo curtinho, elas já ficam me olhando. Elas acham inadmissível fazer uma cirurgia plástica. Se o brinco já é proibido, um piercing então é motivo para um "barraco" dentro da igreja (RIGONI, 2008).

No entanto, se a tentativa de resistência ocorre, há também um movimento, por parte dos mais novos, no sentido de subverter certos padrões. É nesta espécie de movimento de subversão, a partir da compreensão por parte dos fiéis de que a igreja não precisa "ditar" tudo que as transformações vão ocorrendo. As restrições religiosas não desaparecem, mas precisam se "acomodar" às novas vontades e desejos de um "corpo secular".

Nesta lógica, tem sido cada vez mais evidente a necessidade de refletir sobre 0 "descompasso" (ou novo compasso) entre ensinamento institucional e prática religiosa. Mais do que pensar em tais desencontros, é preciso compreender as novas adaptações e acomodações que eles implicam. Em relação às práticas corporais, tanto as instituições religiosas se adaptam à nova demanda de ofertas para o corpo como o próprio indivíduo religioso busca realizar uma espécie de compatibilização entre as ofertas religiosas e as outras tantas que compõem a vida cotidiana na contemporaneidade.

Foi partindo do pressuposto de que o corpo, de modo similar, é a expressão dos diversos arranjos, acomodações ou, ainda, compatibilizações que demandam da vida cotidiana que as análises aqui apresentadas foram pautadas. É, justamente, esta visão de corpo (que expressa tais arranjos) que produz opiniões e visões sobre as práticas corporais e a EF.

\section{A EDUCAÇÃO FÍSICA COMO PRÁTICA "MUNDANA"}

\section{"A Educação Física está o tempo todo provocando o olhar do outro" (Sirléia).}

Ao questionar as meninas selecionadas sobre o que pensam da disciplina $\mathrm{EF}$, bem como aquilo que elas entendem ser os objetivos das aulas e de seus conteúdos, percebemos algumas similaridades entre as suas opiniões. Ainda que elas tenham admitido não entender ao certo o que a EF pretende, todas elas possuem uma narrativa a respeito da disciplina. Um dos exemplos mais interessantes está presente na resposta de Maria:

A EF para mim é o momento de se exercitar. É o momento na escola que a gente aprende a como fazer exercício e cuidar do corpo de um jeito que a gente não tem como fazer em casa, ou não tem como aprender a fazer direito se não for na escola. Aprender os esportes e fazer aula prática, né?

Apesar dos esportes estarem sempre presentes nas falas das meninas, quando questionadas sobre o que a EF ensina, a ideia da disciplina como responsável por ensinar 
a cuidar do corpo teve destaque nas opiniões de Maria. Além disso, sua frase seguinte nos permite perceber os constrangimentos gerados pela prática e a provável dificuldade que alunas na mesma condição sentem em relação a esta disciplina.

Eu gostava de um professor que a gente tinha porque a nota não era baseada só na aula, sabe, ele considerava trabalho escrito, fazia prova. É como se fosse uma aula mesmo, sabe, e não essa aula liberal que a gente tem hoje.

Esta afirmação demonstra uma valorização de atividades que elas, como evangélicas tradicionais, podiam realizar sem problemas. É como se uma aula teórica ou uma prova permitissem sua participação enquanto as atividades práticas não. Lembremos da carta citada anteriormente, em que o pastor proíbe a participação da aluna em aulas práticas, mas permite sua participação em atividades teóricas. O que está em pauta aqui é precisamente o "uso do corpo" e o movimento e não necessariamente o conhecimento produzido pela EF.

Esta noção sobre o que é a EF, apresentada na fala de Maria, representa o modo de pensar de todas as outras meninas estudadas. Mais do que isso, inúmeras pesquisas realizadas demonstram que esta noção de EF parece ser recorrente para a maioria dos alunos das escolas brasileiras e não só para os evangélicos. É preciso deixar claro que, apesar de no âmbito acadêmico e nos projetos pedagógicos das escolas o conceito de EF e seus objetivos serem outros, o entendimento dos alunos, no contexto atual, ainda parece o de uma disciplina que tem como finalidade ensinar os cuidados com o corpo (com a saúde e a beleza) e as modalidades esportivas (restritas ao treinamento e a técnica). Como afirma Werneck (1997), mesmo sem intenção, a EF se torna objeto e alvo de produção de consumo, do corpo bonito, das formas perfeitas. Neste sentido, não são as meninas estudadas que, por serem evangélicas, possuem esta compreensão. Não são elas que constroem uma visão particular sobre o que representa tal disciplina escolar. $O$ que há de particular no caso delas não é a forma como elaboram a noção de EF, mas a forma como outro tipo de conhecimento, gerenciado pela instituição religiosa, entra em tensão com este que elas entendem pertencer ao escopo da EF.

Citemos o exemplo da visão das meninas sobre a dança. Durante nossa estada na escola, numa semana em que o conteúdo trabalhado pelo professor era o samba, elas deixaram claro que seria mais tranquilo estudar e fazer uma prova sobre dança do que realizar aulas práticas sobre este conteúdo tão "mundano" ${ }^{\text {. }}$

Era como se a noção construída sobre o que é a EF fosse propícia à crítica da igreja. O que nos parece mais provável é que os conhecimentos produzidos na igreja pautem as formulações a respeito da EF, digna de crítica ao ser considerada pelo senso comum e, claro, pelas meninas estudadas, como uma disciplina que enaltece a beleza corporal e as diversas práticas corporais. Tal visão de EF torna-se um "prato cheio" para o discurso da igreja, que prega justamente o enaltecimento de valores morais e não físicos. A frase citada como epígrafe deste tópico, sobre a EF provocar o olhar, demonstra de maneira muito clara esta afirmação e o que, de fato, incomoda a igreja quando o assunto é a EF. A exposição e o uso do corpo em práticas tidas como "mundanas" pela igreja parece o ponto-chave da análise.

Após ouvirmos das meninas que a EF é a disciplina que ensina a cuidar do corpo, questionamo-las a respeito das implicações disso no contexto religioso. Dentre as respostas

60 termo "mundano" está constantemente presente na fala dos evangélicos pentecostais. As meninas estudadas explicam que tudo aquilo que não pertence ao "Reino do Senhor" e que não possui relação com o mundo divino/sagrado é considerado mundano (ou do demônio). A oposição entre "divino" e "mundano" aparece repetidamente em seus discursos sobre corpo, EF, movimento, jogo, etc. 
obtidas, todas utilizaram em suas justificativas a separação igreja/mundo e corpo/espírito. Segue um exemplo:

Ficar se preocupando demais com o corpo não é coisa de Deus. 0 pastor até disse uma vez que a gente pode cuidar do corpo, porque se você está feliz com teu corpo você fica bem de espírito também, então esse pastor já é melhor que o outro, entende? Ele não liga muito para isso, mas ele sempre fala que não precisa ter exagero nisso (Letícia).

Letícia compara um pastor com outro, porque sua família acabara de sair da clássica $A D$ e ir para uma igreja mais "moderna": a Igreja Batista Nova Salem. Ao elaborar tal comparação fica evidente que o antigo pastor, da $A D$, era mais conservador. A fala de Letícia nos permite inferir sobre as diferenças entre as diversas denominações e, ainda, perceber certa maleabilidade nas regras, que ocorre com a passagem de uma denominação para outra. Letícia percebe que essa transformação ocorreu somente por causa da troca de uma igreja "mais rígida", segundo ela própria, para uma igreja "mais solta". Almeida (2010) já chamou a atenção para a circulação dos fiéis entre diferentes denominações evangélicas (e até entre diferentes religiões). 0 autor explica que, em busca de certa maleabilidade e flexibilização das regras, vários são os sujeitos que se deslocam para outras igrejas, alimentando, assim, um fenômeno denominado pelo autor de "trânsito religioso".

No entanto, o que parece importar mais em relação à reflexão elaborada acima não é a percepção do afrouxamento das regras da igreja, mas a opinião de Letícia sobre a EF. Ela conta que a disciplina é vista como algo mundano, assim como quase tudo que não pertence ao escopo da igreja. Segundo ela, dentre todas as disciplinas escolares, a EF parece envolver coisas "mais" mundanas que outras. Letícia faz a seguinte afirmação: "Para alguns crentes se eu não uso o corpo para glorificar a Deus, então nem devo usar". Neste sentido, o uso do corpo também está relacionado à ideia do "exibir-se", "ser percebida", chamar a atenção ou, repetindo o que disse Sirléia, do "provocar o olhar do outro". É Sirléia quem também afirma:

Eu acho que as pessoas se exibem muito, não só na aula, claro, mas a aula de EF é uma hora que tem umas meninas que adoram ficar se mostrando, sabe? Umas meninas que se acham gostosonas. A Fabiana mesmo [colega de sala], às vezes vem para a EF com umas calças tão justas e transparentes que dá para ver a calcinha dela. Os meninos ficam todos mexendo com ela (...). Claro que eles gostam de olhar, mas eu acho que eles não namorariam com uma menina desse tipo. Eu não gosto de chamar atenção.

Perguntamos se ela também não chamava a atenção dos meninos, já que era bonita. Ela relembra certa vez, quando ainda ia de saia à escola e alguns garotos comentaram sobre o seu bumbum. Eles diziam que ela tinha uma "bunda boa" e que até ia ficar bem se tirasse aquela saia de "crentinha". Sirléia conta isso com meios sorrisos e finaliza a história dizendo que é por esse e outros motivos que a igreja aconselha o uso de saia, pois ela protege a mulher.

No que diz respeito à vestimenta das meninas evangélicas, ao contrário do que acontecia há cerca de uma década, as meninas dessas denominações, em geral, não são mais obrigadas a usar saia na escola. No entanto, todas comentam sobre a época em que eram obrigadas a fazer uso exclusivo da saia, inclusive durante as aulas de EF.

Quando questionada sobre o porquê de não participar da EF, já que em todos os dias em que observamos as aulas ela ficou sentada, a resposta de Maria foi simples: ela não tinha o costume de participar. 
$\mathrm{Na}$ escola que eu estudava antes, a diretora não obrigava a usar calça, eu era menor, obedecia sem brigar minha mãe, então eu só ia de saia para a aula. Acho que me acostumei a não jogar nada por isso (Maria).

Perguntamos se era apenas por causa da saia que ela não participava e ela respondeu: "É, não tem como ficar à vontade assim, né? Minha mãe me deixava jogar vôlei, mas como, se eu pulava e a saia pulava junto? (risos)".

Tentando ponderar tal resposta, como se tentasse não deixar a culpa toda na igreja e na mãe, ela explica que não era apenas por causa da igreja que ela não participava das aulas. Desde o início demonstrando ser a mais "rebelde" das meninas estudadas, ela elabora um discurso no qual faz questão de demonstrar que a igreja não é o "fio condutor" de sua vida cotidiana.

Eu acho que a igreja cuida da minha pessoa espiritual, da minha alma. A EF me ensina a cuidar da minha pessoa física, do meu corpo. Para a minha Igreja, eu sei que eles acham que só tem que se preocupar com a alma. Mas eu, Maria, acho que a gente tem que cuidar sempre dos dois juntos. $O$ que é que adianta a gente cuidar da alma e não cuidar da vida? A gente tem que viver (Maria).

O interessante em sua fala é a forma como ela opõe o ato de "cuidar da alma" ao de "cuidar da vida". Trata-se, basicamente, da mesma oposição corrente entre aquilo que é da igreja e o que é mundano, mas a maneira como ela formula deixa clara uma posição tomada diante dessas oposições. É como se ela afirmasse que mesmo algo sendo "do mundo" pode ser necessário e, mais do que isso, pode ser desejado por ela de forma legítima. A fala de Maria demonstra que em sua concepção de vida a igreja está "fora", como algo à parte. Tal comportamento assemelha-se ao fenômeno analisado por Hervieu-Léger (1999), quando esta percebe, já na década de 1990, que a religião deixa de se constituir como um código único ou principal no que diz respeito à imposição dos sentidos da vida e dos comportamentos diários daqueles que assumem alguma filiação religiosa.

Após um comentário semelhante ao de Maria, Ana Julia afirmou que sentia muita vontade de participar das aulas de EF sempre que sentava e via os colegas jogarem. Certa vez, após conversar com sua mãe, tomou a decisão de contar ao pastor sobre os constrangimentos pelos quais passava por não participar, inclusive em relação à cobrança do professor, que sempre insistia para que ela mudasse de atitude e passasse a realizar as atividades. Nesta ocasião, a resposta do pastor não foi necessariamente negativa. Ele consentiu sua participação em algumas atividades, como o vôlei, por exemplo, no entanto, não permitiu que ela utilizasse calça para ir às aulas. Ao questioná-la sobre o porquê da decisão do pastor, ela explicou que para ele isto poderia "denegrir" a imagem da igreja. Além disso, segundo o pastor, diz ela: "Deus não gosta destas atitudes e em casos como este o espírito santo deixa de habitar 0 corpo da pessoa".

Perguntando se ela achava que esse tipo de proibição tinha a ver somente com o modo de se vestir, uma vez que o pastor permitiu sua participação apenas em algumas atividades, não foi de Ana Julia que obtivemos resposta, mas de Letícia, que estava ao seu lado no momento e num tom indignado interrompeu a colega respondendo:

Claro que não é só por causa da saia. $\mathrm{Na} A D$ as mulheres são tudo mais paradinha mesmo. Acho até estranho o pastor ter deixado ela jogar vôlei. Uma vez, quando a gente ainda ia na $A D$, a minha irmã disse para o pastor que ia jogar só vôlei, porque não tinha contato corporal como o futebol e tal, mas ele disse que era uma 
atividade muito vulgar. Ele dizia que tem um monte de movimento de levantar, abaixar. Não sei aonde, mas tudo bem.

Ana Julia apenas completa o raciocínio de Letícia dizendo: "Aí não sobra nada, né? Que nem quando tinha passeio na escola, por exemplo, que tinha que ir de calça, eu não ia (referindo-se a passeio em bosques)".

Diferente da maneira "rebelde" com que Maria tece seus comentários, mas de forma a demonstrar que não concorda com tudo, Ana Julia contesta:

Eu me cuido e faço as coisas como eu acho que devo, mas tem coisas que eu relaciono com a igreja sim. $A$ gente acaba ouvindo tanto, que faz isso o tempo todo. Não tem como não lembrar daquilo que a gente aprende. Mas eu não engulo tudo, não. Tem gente que acha que ficar jogando bola é coisa muito praticada no mundo, mas eu acho que não tem nada a ver. Eu não faço porque eu não gosto e não por causa da igreja. Eu não me enturmei quando era hora, agora já tá meio tarde para fazer (Ana Julia).

Ao analisarmos os últimos comentários das meninas, a sensação era de que algumas coisas que elas diziam soavam inacabadas. Ao mesmo tempo em que elas pareciam indignadas com certos impedimentos baseados nas condutas religiosas, as normas da igreja pareciam uma ótima justificativa para os momentos em que elas simplesmente não tinham vontade de participar da aula (fato corrente na EF e não é exclusividade das meninas evangélicas). A questão que pulsava era: o que elas não estão contando e por quê? Pina Cabral (2008) chama a atenção sobre a importância do pesquisador estar atento ao que denomina de "não ditos". É como se para nós as meninas quisessem demonstrar mais autonomia do que de fato possuíam.

Enfim, o que queremos dizer é que está claro que o discurso das meninas é elaborado de tal forma porque elas são levadas a uma reflexão notadamente justificada pela nossa presença. Elas sabiam do que se tratava a pesquisa e imaginavam o que queríamos saber. Mas é justamente nesta hora que elas exercem seu poder de reflexão e decisão. Se as suas práticas diferem de seus discursos é o ponto que menos importa neste momento da análise. Pois é no discurso que se concretiza uma elaboração por parte das meninas daquilo que elas foram forçadas a pensar justamente no exercício de estarem conosco. Se, por um lado, é um exercício de alteridade para nós, como pesquisadores, é também para elas, que fazem uma leitura do contexto e elaboram as respostas no momento do encontro.

Se este é o momento tenso da pesquisa, em que é necessário perceber os ajustes entre aquilo que se observa e aquilo que o "nativo" pensa e fala, este é também o seu momento mais rico, no qual o desafio é elaborar uma interpretação equilibrada. Como sugere Geertz (1989), para desvendar os sistemas simbólicos que orientam a vida social é necessário confrontar o que se observa com o que se ouve. No caso dos exemplos citados, o importante é a demonstração das meninas, ainda que não na prática, da necessidade de acomodação, neste caso, entre 0 agenciamento religioso do corpo e aquele promovido pela EF.

Ao analisarmos as narrativas exemplificadas até aqui, percebemos que algo muito diferente do que acontecia há cerca de uma década - quando iniciávamos os estudos sobre corpo, EF e religião - estava se configurando. Já havíamos dado conta de que a religiosidade estava mudando, como demonstram os exemplos citados ao longo do texto. Mas o que pudemos notar é que agora o que se modificava não era a compreensão e narrativa das meninas sobre a igreja e seus costumes e sim a sua visão sobre a EF (RIGONI, 2013). Percebemos, ao longo 
da pesquisa, que a maneira como elas viam a EF ia se transformando e/ou tomando novas proporções.

As meninas estudadas estavam atrelando à EF uma função de educar para a saúde, mas, acima de tudo, para a estética. Discursos que relacionam a EF ao ato de "malhar", ficar bonita, "gostosa", saudável e, ainda, aqueles discursos que a relacionam com a prática de exercício físico ocupam maior espaço no discurso destas meninas nesta fase da vida (ensino médio). Isto não acontecia com as meninas estudadas em anos anteriores, em idade inferior (ensino fundamental), as quais não estabeleciam uma relação tão direta entre a disciplina de EF e a educação para a estética.

As questões que originaram tais transformações podem ser múltiplas e complexas. Mas, quando as meninas relacionam as aulas de EF a um corpo bonito, à sensação de prazer ao participarem de determinadas práticas corporais em horários e locais de lazer e aos cuidados com o corpo, de maneira geral, parece mais fácil entender as preocupações presentes no discurso religioso.

Interessante é o modo como elas constroem uma noção de EF de forma que suas características se tornam passíveis de "implicância" e até da rejeição por parte da igreja.

Você pode se cuidar, cuidar da saúde, só não pode fazer coisa vulgar e pensar só na beleza. Por exemplo, eu posso ir para a academia se quiser, mas pela saúde, não pra ficar gostosa (Ana Julia).

No entanto, quando questionada se conhecia alguém da igreja que frequentava a academia, a resposta de Ana Julia foi a de que no momento não se lembrava de ninguém.

\section{REFLEXÕES SOBRE A EDUCAÇÃO FíSICA ESCOLAR}

É interessante notar que as meninas atribuem à EF Escolar a tarefa de educar o corpo e as práticas corporais para a vida extraescolar. Como pode ser exemplificado na fala a seguir: "Eu acho que ela tem que ensinar a gente a se cuidar, não só na escola, mas sempre. A gente tem que ter uma preocupação com o corpo e tal. Por questão de saúde, de estética, estas coisas" (Renata). Se, por um lado esta preocupação demonstra uma relação da EF com a vida pós-escolar, por outro lado é necessário refletirmos sobre os motivos pelos quais a disciplina aparece vinculada a valores exacerbados da aparência física.

Gonzáles e Fensterseifer (2010) afirmam que a EF como disciplina escolar deve proporcionar ao aluno a reflexão acerca da dimensão cultural, devendo, portanto, potencializar uma relação mais lúcida com o mundo. Os autores ainda afirmam que os saberes da experiência não podem ser substituídos pela reflexão conceitual. Compreendemos, deste modo, que a EF deve visar um alargamento da compreensão de corpo humano e garantir o acesso e a vivência de práticas corporais produzidas ao longo da história.

Esse alargamento das experiências corporais já é preconizado por Valter Bracht (1997, p. 22), há alguns anos, quando este afirma que a EF deve estar preocupada com a educação da sensibilidade, "o que significa dizer 'incorporação' não via discurso, e sim via 'práticas corporais"'. Ela deve possibilitar ao aluno a experiência do gesto. Esta afirmação nos remete à ideia desenvolvida por Le Breton (2009), quando, ao elaborar uma "antropologia das emoções", argumenta sobre as possibilidades de uma experiência afetiva do movimento. Acreditamos que 
o professor deve garantir esta experiência (afetiva) na escola para que fora dela ela possa ter prosseguimento, pois entendemos que a EF deve preparar o aluno para o mundo do lazer e para a vivência das práticas lúdicas para além da idade escolar.

Em contrapartida, não há como não fazer menção a outras formas de entender a EF na escola, presentes na área. Ao longo da história a EF vem sendo relacionada a temas que dizem respeito à beleza (sempre associada à magreza), à força física, às formas "bem definidas", à habilidade motora, ao rendimento, etc. $O$ que queremos pontuar é que este tipo de saber, mesmo sendo contraditório àquele difundido por professores e pesquisadores que pensam a área a partir das Ciências Humanas, é ainda muito recorrente nas escolas brasileiras. $O$ fato é que tanto este tipo de saber como aqueles baseados em pressupostos "mais humanos" parecem, em determinados momentos, contraditórios com aqueles conhecimentos e normas propagados pela instituição religiosa, gerando o que chamamos, ao longo do texto, de "tensão". Entendemos que este argumento se aplica de forma mais intensa em igrejas pentecostais mais tradicionais, em que o ensinamento e a prática possuem pretensões mais rígidas em relação ao comportamento dos fiéis, como é o exemplo das igrejas estudadas. Neste sentido, a instituição religiosa, que sempre esteve interessada na "beleza da alma", torna-se passível de uma relação conflituosa com a EF, que, ao longo da história, ensinou a valorizar as preocupações com o corpo.

Se a EF aparece, constantemente, vinculada à ideia do corpo bonito, das formas perfeitas, é preciso, como afirma Werneck (1997, p.322), "construir conhecimentos e vivências teórico-práticas, que também se materializam pelo desejar e pelo prazer com sabor de liberdade, despertando o corpo para uma totalidade muitas vezes desconhecida", esses saberes podem, ora ou outra, entrar em tensão (incomodar) com o saber repassado pela igreja dos sujeitos estudados, pois pode aflorar o número de sensações corpóreas e, segundo a autora, despertar para o prazer carnal.

Se, concordando com a autora, certas práticas podem remeter a situações de prazer, é fato, também, que muitas vezes ocorre o oposto. Não há como negar que muitas vezes na EF o corpo é o objeto do controle, da manipulação. Não causa surpresa o fato de uma aula de EF ser o lugar onde o corpo é forçado, testado, controlado. Em muitas ocasiões, longe do prazer, as sensações aparecem vinculadas à dor, ao sofrimento, etc. Neste sentido, o incômodo que a EF pode causar à concepção religiosa não diz respeito apenas ao prazer, mas ao modo como o corpo passa a ser utilizado. Como lembram as meninas estudadas, se não for para servir a Deus e sim para servir nossos impulsos, então isto é pecado.

Por fim, parece claro o fato de a EF engendrar certas tensões entre seus conhecimentos e aqueles produzidos em determinadas igrejas evangélicas. Resta refletirmos sobre que tipos de tensão desejamos produzir. Acreditamos que elas podem ser desnecessárias quando geram relações conflituosas às alunas, no sentido de atrelarem-na a funções estéticas, por exemplo. Cremos, no entanto, que algumas tensões podem ser "benéficas" ao produzirem reflexões sobre o corpo e as práticas corporais. Se para os evangélicos o corpo deve ser utilizado apenas como forma de servir a Deus, a EF pode proporcionar outras experiências relacionadas à corporeidade. 


\section{REFERÊNCIAS}

ALMEIDA, Ronaldo de. Religião em Transição. In: HORIZONTES das Ciências Sociais no Brasil: antropologia. São Paulo: ANPOCS, 2010. p. 367-405.

BRACHT, Valter. Educação Física: conhecimento e especificidade. In: SOUZA, Eustáquia Salvadora; VAGO, Tarcísio Mauro. Trilhas e partilhas: educação física na cultura escolar e nas práticas sociais. Belo Horizonte: Cultura, 1997. p. 13-23.

FONSECA, Claudia. Quando cada caso não é um caso: pesquisa etnográfica e educação. Revista Brasileira de Educação, n. 10, p.58-78, jan./abr.1999.

FRESTON, Paul. Nem anjos nem demônios: interpretações sociológicas do pentecostalismo. Petrópolis: Vozes, 1996.

GEERTZ, Clifford. A interpretação das culturas. Rio de Janeiro: Guanabara Koogan, 1989.

GONZÁLES, Fernando; FENSTERSEIFER, Paulo Evaldo. Entre o "não mais" e o "ainda não": pensando saídas do não-lugar da EF escolar I. Cadernos de Formação RBCE, p. 9-24, set. 2009.

HERVIEU-LÉGER, Danièle. 0 peregrino e o convertido: a religião em movimento. Lisboa: Gradiva, 1999.

LE BRETON, David. As paixões ordinárias: antropologia das emoções. Petrópolis, RJ: Vozes, 2009.

MAUSS, Marcel. Sociologia e antropologia. São Paulo: Cosac Naify, 2003.

PINA CABRAL, João. Sem palavras: etnografia, hegemonia e quantificação. Mana, n. 14, p. 61-86, 2008.

PIERUCCI, A. F. Reencantamento e Dessecularização: a propósito do auto-engano em sociologia da religião. Novos Estudos CEBRAP, n. 49, p. 99-117, nov. 1997.

RIGONI, Ana Carolina Capellini. Corpos na escola: (des)compassos entre a educação física e a religião. Campinas, SP. 2013. 175f. Tese (Doutorado em Educação Física) - Faculdade de Educação Física, Universidade Estadual de Campinas, Campinas, 2013.

RIGONI, Ana Carolina Capellini. Marcas da religião evangélica na educação do corpo feminino: implicações para a Educação Física Escolar. 2008. 162f. Dissertação (Mestrado em Educação Física) - Faculdade de Educação Física, Universidade Estadual de Campinas, Campinas, 2008.

TECHIO, Kachia. Transformando a água em sangue: uma análise sobre a exportação evangélica brasileira através das performances da IPDA. 2011. 346f.Tese (Doutorado) - Faculdade de Ciências Sociais e Humanas, Universidade Nova de Lisboa, Lisboa, 2011.

WERNECK, Cristiane Luce Gomes. Educação Física: novos olhares sobre o corpo. In: SOUZA, Eustáquia Salvadora; VAGO, Tarcísio Mauro. Trilhas e Partilhas: educação física na cultura escolar e nas práticas sociais. Belo Horizonte: Cultura, 1997. p. 299-326. 